\title{
Cytogenetic Study In Male Infertility
}

\author{
Drugkar Amol Z. ${ }^{1 *}$; Gangane S.D. ${ }^{2}$; More Rakhi M. ${ }^{3}$; Drugkar Swati A. \\ ${ }^{I^{*}}$ Asst. Prof., Dept. of Anatomy, Dr. PDMMC, Amravati, India \\ ${ }^{2}$ Prof. \& Head, Dept. of Anatomy, GMC, Mumbai, India \\ ${ }^{3}$ Asst. Prof., Dept. of Anatomy, KJSMC, Mumbai, India \\ ${ }^{4}$ Medical Officer, Lata Mangeshkar Hospital, Nagpur, India
}

\begin{abstract}
The present study was carried out to find out frequency of chromosomal abnormalities \& contribution of environmental, occupational factors in cases of male infertility. 70 males referred for complaints of infertility were included in the present study. The study was carried out in the following steps. 1) Selection of patients 2) Clinical examination of patients 3) Collection of blood and karyotyping 4) Photomicrography 5) Data tabulation and Analysis \& 6) Collection of buccal smear for Sex Chromatin Study. Cytogenetic analysis of the infertile males revealed that chromosomal abnormalities were present in 9 patients (12.85\%). Among the chromosomal abnormalities, Numerical abnormalities were present in 6 patients (8.57\%) and Structural abnormalities were present in 3 patients (4.28\%). Among the Numerical abnormalities, most common were 47, $X X Y(2)$ and $46, X X(2)$. Mosaicism i.e. 46,XY(20\%)/47,XXY(80\%) was seen in one patient. One patient showed a karyotype of 47,X,i $(X q) Y$. Among the 3 patients with structural abnormalities, one patient showed a 45,XY,-22 $t$ (14/22) karyotype, one patient showed 46,XY, inv(9) and one patient showed 46,XY, large $Y$.
\end{abstract}

Key Words: Karyotype, Chromosome, Infertility

\section{Introduction}

Infertility is disorder of reproduction representing a significant social, medical \& economic burden for individual \& the society ${ }^{14}$. It affects on average $25 \%$ couples worldwide. Of these $15 \%$ couples seek medical treatment for infertility \& less than $5 \%$ remains unwillingly childless ${ }^{31}$. Approximately 1 in 10 couple in the United States is infertile \& each partner is equally likely to be affected ${ }^{14}$.

In India also infertility is a common \& distressing problem, except that infertile couples report late for evaluation $^{33}$. Infertility affects $10-15 \%$ of couples of childbearing age, and nearly half of these cases are attributable to the male partner and particularly sperm related problems. Approximately $10 \%$ of infertile men are azoospermic. A large majority of these men have associated genetic disorders that range from chromosomal (gonosomal) aneuploidy or structural rearrangements to mutations or microdeletions. In infertile men with a chromosomal abnormality, $2.7 \%$ shows oligospermia \& $10.8 \%$ shows azoospermia. Chromosomal aberrations are mainly represented by sex chromosomal defects, which are twice as high in infertile men compared with controls ${ }^{17}$. There are various causes of infertility such as anatomical, pathological, environmental \& occupational. In a sizeable proportion of cases, a genetic or chromosomal disorder forms the underlying basis of infertility. Unexplained infertility should prompt a request for chromosomal studies. At least 5\% of azoospermic males have been found to have Klinefelter syndrome.

Formerly, females alone shouldered the responsibility for infertility. Today, however, it is realized that the male is equally likely to be affected as his mate. Male \& female factors contribute equally to infertility in a couple $^{16}$. The overall incidence of chromosomal factors in infertile males ranges from $2 \%$ to $8 \%$, with a mean value of 5\%. The chromosomal abnormalities include sex chromosomal abnormalities are predominating in azoospermic men, but a wide range of structural autosomal anomalies, including Robertsonian \& reciprocal translocations, inversions, duplications \& deletions are also found in infertile males ${ }^{11}$.

\section{Aim Of Present Study}

Reviewing the existing literature it was concluded that males is equally likely to be affected as his mate. Hence the present study was carried out to find out frequency of chromosomal abnormalities in cases of male infertility.

\section{Material And Methods}

The study was carried out in a tertiary care hospital. Among the different cases referred to genetic division of the institute, 70 males referred for complaints of infertility were included in the present study. Patients were explained the procedure and possible outcome of the test. A written and informed consent of the patients was taken. The study was carried out in the following steps.

1. Selection of patients 
Male patients referred to the genetic division for infertility with history of inability to have an issue after one year of marriage without use of any contraception and/or erectile dysfunctions were included in present work.

2. Clinical examination of patients

3. Collection of blood and karyotyping

Blood was collected for karyotyping and slides were prepared which were then examined. In addition sex chromatin study of the patients was studied by collecting the buccal smears.

4. Photomicrography

Photographs of appropriate abnormal metaphases were taken for documentation.

5. Data tabulation and Analysis

The collected data was tabulated.

6. Pedigree Charting

It is a short hand method of expressing family data. Detailed pedigree charting was done to know how a particular trait was segregating within the family. It also helped in identification of other family members that were affected.

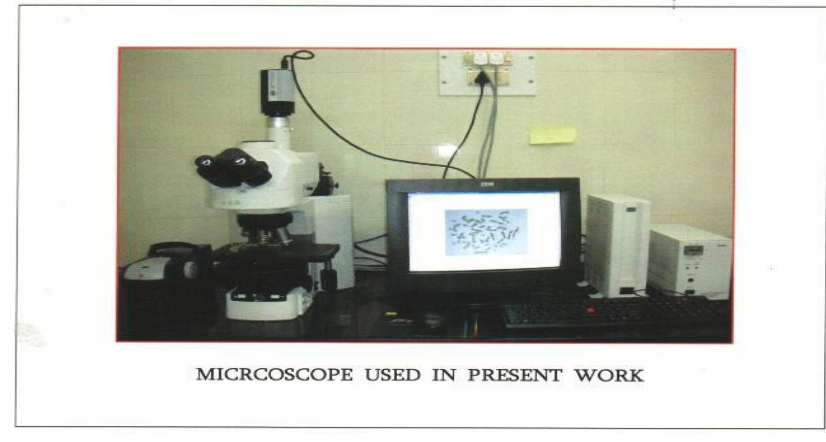

\section{Observations And Results}

A total of 70 patients with infertility were evaluated retrospectively. Nine out of $70(12.85 \%)$ patients showed chromosomal alteration. Among the chromosomal abnormalities, Numerical abnormalities were present in 6 patients (8.57\%) and Structural abnormalities were present in 3 patients (4.28\%). Among the 6 patients with Numerical abnormalities, Two patients (2.85\%) showed 47,XXY karyotype which is accepted to be a variant in the population. 2 patients $(2.85 \%)$ were found with a 46,XX karyotype; one patient (1.43\%) was found with Mosaicism i.e. 46,XY(20\%)/47,XXY(80\%); one patient (1.43\%) showed a karyotype of 47,X,i (Xq)Y. Among the 3 patients with structural abnormalities, one patient (1.43\%) showed a 45,XY,-22 t (14/22) karyotype; one patient (1.43\%) showed 46,XY, inv(9); one patient (1.43\%) showed 46,XY, large Y.

Table 1: Showing Distribution of Chromosomal Study in Present Study

\begin{tabular}{|c|c|c|}
\hline Karyotype & Total No. of Patients $(\mathbf{n}=\mathbf{7 0})$ & Percentage \\
\hline Normal & 61 & 87.15 \\
\hline Abnormal & 09 & 12.85 \\
\hline
\end{tabular}

Table 2: Showing Distribution of Chromosomal Study in Present Work

\begin{tabular}{|c|c|}
\hline Karyotype & Total No. of Patients(n=70) \\
\hline $46, \mathrm{XY}$ & 61 \\
\hline $47, \mathrm{XXY}$ & 02 \\
\hline $46, \mathrm{XX}$ & 02 \\
\hline $46, \mathrm{XY}(20 \%) / 47, \mathrm{XXY}(80 \%)$ & 01 \\
\hline $47, \mathrm{X}, \mathrm{i}(\mathrm{Xq}) \mathrm{Y}$ & 01 \\
\hline $46, \mathrm{XY}, \operatorname{inv}(9)$ & 01 \\
\hline $45, \mathrm{XY},-22 \mathrm{t}(14 / 22)$ & 01 \\
\hline $46, \mathrm{XY}, \operatorname{largeY}$ & 01 \\
\hline
\end{tabular}

Table 3: Showing Distribution of Chromosomal Abnormalities

\begin{tabular}{|c|c|}
\hline Type of abnormality & Karyotype \\
\hline & $46, \mathrm{XY}, \operatorname{inv}(9)$ \\
\hline
\end{tabular}




\begin{tabular}{|c|c|}
\hline \multirow{2}{*}{ Structural abnormality } & $45, \mathrm{XY},-22 \mathrm{t}(14 / 22)$ \\
\cline { 2 - 2 } Numerical abnormality & $46, \mathrm{XY} .1 \mathrm{argeY}$ \\
\hline \multirow{3}{*}{ No } & $47, \mathrm{XXY}$ \\
\cline { 2 - 2 } & $46, \mathrm{XY}(20 \%) / 47, \mathrm{XXY}(80 \%)$ \\
\cline { 2 - 2 } & $47, \mathrm{X}, \mathrm{i}(\mathrm{Xq}) \mathrm{Y}$ \\
\cline { 2 - 2 } & $46, \mathrm{XX}$ \\
\hline
\end{tabular}

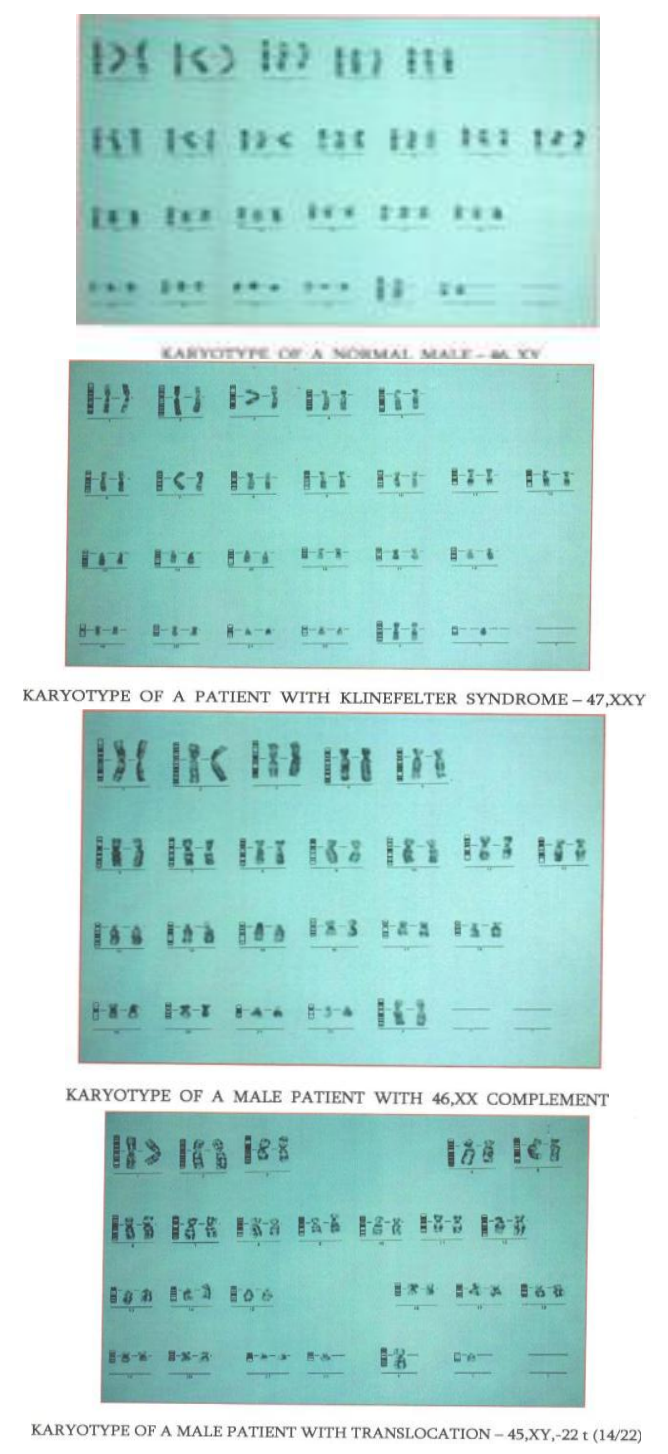

\section{Discussion}

Indian civilization is one of the most ancient civilizations. During the entire history of our subcontinent, the emphasis on the family has been paramount and family means children. Thus, having a child has been of the greatest importance not only to the couple but also to their larger family. Socially, a stigma is attached to a couple, if the couple does not have a child ${ }^{27}$.

The perception of the degree of male involvement in infertility has undergone a number of revisions during the past 50 years. Initially, infertility was considered primarily a female problem. This no more holds true and it has lead to the fact that $40-50 \%$ of infertility is wholly or in part due to a male factor ${ }^{28}$. Lunenfeld B. and Insler V. ${ }^{19}$ (1993) reviewed the causes of infertility and the dimensions of the problem. In most of the countries around the world the male counterpart was responsible in $23 \%$ to $46 \%$ of the infertile couples. This data is shown in table No. 4

Table No.4 showing the incidence of male infertility.

\begin{tabular}{|c|c|c|c|c|}
\hline Author & Year & Country & No. of Patients & Male causes \\
\hline Nakamura et al & 1975 & Brazil & 1000 & $27.9 \%$ \\
\hline
\end{tabular}




\begin{tabular}{|l|l|l|l|l|}
\hline Cox & 1975 & Australia & 900 & $26.2 \%$ \\
\hline Cocev & 1972 & Bulgaria & 744 & $40.9 \%$ \\
\hline Ratnam et al & 1976 & Singapore & 709 & $23.1 \%$ \\
\hline Dor et al & 1977 & Israel & 665 & $27.9 \%$ \\
\hline Insler et al & 1981 & Israel & 583 & $30.2 \%$ \\
\hline Raymount & 1969 & Canada & 500 & $26.2 \%$ \\
\hline Gunarate & 1979 & Srilanka & 393 & $41.6 \%$ \\
\hline Anderson & 1968 & Denmark & 183 & $46.6 \%$ \\
\hline Present Study & $\mathbf{2 0 0 7}$ & India & $\mathbf{7 0}$ & $\mathbf{2 7 . 1 4 \%}$ \\
\hline
\end{tabular}

The above table shows the comparison between the causes of infertility due to male factor studied by different authors. Thus the present study correlates with the study of the previous authors.

Despite the prevalence of infertility only recent research has focused onto genetic factors accounting for infertility. It is now clear that genetic abnormalities are present in about $15 \%$ of male infertile subjects. They include chromosome aberrations and single gene mutations ${ }^{11}$.

It has been known for some 20 years that the prevalence of chromosomal abnormalities is higher in infertile men, this figure being inversely related to the sperm count ${ }^{11}$.

The rate of chromosomal aberrations in the general population is less than $1 \%$ while it is higher in patients with poor reproductive history ${ }^{8}$. Chromosomal abnormalities have been detected in $2.1-8.9 \%$ of men attending infertility clinics ${ }^{9}$.

The chromosomal abnormalities found in infertile men are structural, numerical or mosaicism ${ }^{8}$. Sex chromosomal abnormalities predominate in male infertility ${ }^{27,29}$. The single sex chromosomal abnormality of 47 , $\mathrm{XXY}$ and mosaics of 46,XY/47, XXY are relatively common and are seen more likely in azoospermic as well as in severe oligospermic males. The gonadal defect in XXY men is related to germ cell survival and sex chromosome constitution ${ }^{27}$. Testicular maldevelopment can be found in association with Klinefelter syndrome. Males with the latter genetic abnormality (XXY) usually have small testes and azoospermia ${ }^{28}$.

Van Assche $^{29}$ (1996) investigated 694 infertile men for chromosomal causes and found that sex chromosomal abnormalities (47, XXY) predominate in male infertility.

Quilter et $\mathrm{al}^{25}$ (2003) suggested that routine cytogenetic analysis of infertile male patients is required. In their study of patients they found 2 patients $(1.9 \%)$ with Klinefelter syndrome.

Weiss et al found that the most frequent karyotype abnormality in male patients is Klinefelter syndrome which occurs in approximately 1 in every 500 males $^{21}$.

Sayee Rajangam et $\mathrm{al}^{26}$ (2006) studied 73 infertile males referred for chromosomal analysis. They found 8 (10.95\%) patients with karyotype 47, XXY.

Duzcan et $\mathrm{al}^{8}$ (2003) found $1(1.58 \%)$ male out of 63 with a karyotype 47, XXY.

Ambasudhan et $\mathrm{al}^{4}$ (2003) studied 180 azoospermic / oligospermic patients and found out 6 (3.33\%) patients with 47, XXY.

In the present study, 47,XXY karyotype was seen in $2(2.85 \%)$ patients . In both these patients seminal studies showed azoospermia. Barr body was present in both patients. Hormonal study showed raised LH and FSH levels and reduced testosterone. Both patients had significant clinical features i.e. bilateral gynaecomastia, small testes and delayed secondary sexual characters. These findings are classically found in patients of Klinefelter syndrome.

Thus the present study correlates with the findings of Ambasudhan et al (2003), Duzcan et al (2003) and Quilter et al (2003).

Sayee Rajangam et $\mathrm{al}^{26}$ (2006) found 2 patients $(2.73 \%)$ with a mosaic pattern.

Ambasudhan et $\mathrm{al}^{4}(2003)$ found 2 mosaics $(1.11 \%)$.

In the present study, 46,XY/47,XXY mosaic Klinefelter was seen in $1(1.42 \%)$ patient.

Thus the present study correlates with the findings of Ambasudhan et al (2003) and Sayee Rajangam et al (2006).

The second most commonly found chromosomal abnormality in the present study was 46,XX from the phenotypic male patients.

The 46,XX maleness is characterized by testicular development despite the lack of normal $\mathrm{Y}$ chromosome. The frequency of XX males in the general population is very low $(1$ in 10,000) whereas they are found more frequently in azoospermic men ${ }^{27}$.

The etiologies proposed to explain the XX maleness are ${ }^{27}$

- Translocation of sex determining region Y-gene (SRY), from Y chromosome to the distal part of the short arm of the $X$ chromosome during meiosis (Van der Auwera 1992). 
- Mutation in an autosomal or $\mathrm{X}$ chromosome gene which permits testicular determination in the absence of SRY (Ferguson Smith 1990).

- Undetected 46,XX / 47, XXY mosaics or other mosaics with the Y bearing cell line.

Nishino et $\mathrm{al}^{20}$ (1993) studied a 24-year-old infertile male. Semen analysis revealed azoospermia. Endocrinological examination showed elevated serum LH and FSH and low level of serum testosterone. Testicular biopsy disclosed atrophic seminiferous tubules. Abdominal computed tomography revealed no ovaries or uterus. The chromosomal analysis revealed a karyotype of 46XX. This case was diagnosed as a case of 46XX male.

In the present study 2 patients (2.85\%) were found with a 46,XX karyotype. In both these patients seminal studies showed azoospermia. Barr body was present in both patients. Hormonal study showed raised LH and FSH levels and reduced testosterone. Both patients had significant clinical features i.e. bilateral gynaecomastia, small testes and delayed secondary sexual characters. Among these two patients, one had marked hypospadias. Thus the findings in present study correlate with those found by Nishino et al (1993) in 46,XX male.

Structural abnormalities involving Y chromosome are found to be higher in infertile males and more so in azoospermic males. Structural abnormalities like dicentric $\mathrm{Y}$, a ring $\mathrm{Y}$ chromosome and the pericentric inversion of the $\mathrm{Y}$ chromosome are associated with spermatogenic failure.

In a study conducted by Sayee Rajangam et $\mathrm{al}^{26}$ (2006), they found out 1 patient with large $\mathrm{Y}$ out of 73 patients. Ismail et $\mathrm{al}^{16}$ (1993) studied 100 infertile males and found out $10 \%$ males with large Y. They suggested that such $\mathrm{Y}$ chromosome abnormalities were frequent among azoospermic than oligospermic males.

In the present study 1 patient showed a karyotype $46, \mathrm{XY}$ with large $\mathrm{Y}$. This study correlates with the study conducted by Sayee Rajangam et al (2006).

In our patient semen analysis was found to be normal and this does not correlate with the study conducted by Ismail et al (1993).

Isochromosome is the resultant of an abnormal split of the centromere (horizontal instead of vertical) followed by duplication of one of the arm.

Badovinac et $\mathrm{al}^{5}$ (2000) studied 782 patients with fertility problems. On chromosomal analysis, he found 2 patients with $46, \mathrm{X}, \mathrm{i}(\mathrm{Xq}) / 45, \mathrm{X}$ karyotype.

Sayee et $\mathrm{al}^{26}(2007)$ found 1 patient with $45, \mathrm{X} / 46, \mathrm{X}, \mathrm{i}(\mathrm{Xq})$ among 83 chromosomally abnormal patients.

In present study, one patient showed a karyotype $47, \mathrm{X}, \mathrm{i}(\mathrm{Xq}) \mathrm{Y}$. Thus the chromosome complement revealed an isochromosome involving ' $q$ ' arm of ' $X$ ' chromosome. The semen analysis of the patient with 47, X,i(Xq) Y showed azoospermia. This patient was Barr body positive. On hormonal study this patient showed raised LH levels and clinical examination showed a small penis, undescended testes on the right side and a small testis on the left side.

In infertile males, translocations are reported in $1.2 \%$ cases. These may be Robertsonian $(0.7 \%)$ or Reciprocal $(0.5 \%)$. Robertsonian translocations are frequently observed in oligospermic patients $(1.6 \%)$. Also $0.9 \%$ reciprocal translocations are found in azoospermic and $0.8 \%$ in oligospermic men $^{27}$. Spermatogenic impairment is related to an increase in the frequency of the $\mathrm{XY}$ bivalent and the Robertsonian trivalent association during the pachytene stage. Translocation is the most commonly observed chromosomal abnormality. Overall, $75 \%$ are autosomal balanced translocation in the couples with pregnancy loss and this incidence is supposed to be thirty times higher than the report in the general population ${ }^{26}$.

Forej $^{10}$ (1974) suggested that non random association might produce interference with precocious $\mathrm{X}$ chromosome inactivation in the primary spermatocytes which would be required for normal spermatogenesis.

Yoshida et $\mathrm{al}^{32}$ (1997) studied 1007 males with infertility and found out $18(1.79 \%)$ patients with translocations. Baschat et $\mathrm{al}^{6}$ (1996) studied 32 patients of male infertilitry and found $2(6.25 \%)$ patients with a translocation. Haidl et $\mathrm{al}^{13}$ (2000) studied 305 infertile males and found 10 (3.27\%) patients with translocation.

Carp et $\mathrm{al}^{7}$ (2004) studied 458 males referred for infertility. Translocation was observed in 21 (4.58\%) patients. Quilter et $\mathrm{al}^{24}$ (2005) found 2 (1.94\%) patients of Robertsonian translocation in 103 patients.

Sayee et $\mathrm{al}^{26}$ (2006) found $2(2.73 \%)$ patients of reciprocal translocation among 73 infertile males.

In the present study, translocation $45, \mathrm{XY},-22 \mathrm{t}(14 / 22)$ was found in $1(1.42 \%)$ patient. The other significant features which were of importance in this patient were the raised FSH \& LH levels, reduced testosterone and oligospermia.

Thus the present study correlates with the findings of Yoshida et al (1997), Haidl et al (2000), Quilter et al (2005) and Sayee et al (2006).

Paracentric and pericentric inversions are often reported in infertile males. Inversions of chromosome 1-3, 5-7 and 9 have been reported ${ }^{102}$. Chandley et al studied patients with inversion in chromosome 1 and found out 
extensive disturbance of synapses across the inverted region at metaphase I resulting in a loop formation. The infertility effects of chromosome I inversion could be due to germ cell maturation impairment because of the failure of synapses.

Yoshida $^{32}$ (997) studied 1007 patients and found 5 patients $(0.49 \%)$ with inversion.

Carp et $\mathrm{al}^{7}$. (2004) investigated 458 patients of male infertility and found 20 (4.36\%) patients with inversions.

Quilter et $\mathrm{al}^{24}$ (2005) studied 103 infertile males. They found inversion in $2(1.94 \%)$ patients.

In a French Collaborate Study conducted in 1986, a data from different laboratories was collected to find the incidence of inversion. It was found that out of the total 305 patients, inversions were seen in $138(45.24 \%)$

patients. Maximum number of inversions were seen in chromosome 2 (87), others were chromosome 5 (22) and chromosome 10(29).

In the present study inversion was found in 1 patient (1.42\%). The karyotype was 46, XY, inv(9).

Thus the present study correlates with the findings of Yoshida (1997), Quilter et al (2005).

Table 5: Showing incidence of chromosomal abnormality in Male Infertility

\begin{tabular}{|l|l|c|c|c|}
\hline Author & Year & Total No. of Patients & $\begin{array}{l}\text { Chromosomal } \\
\text { Abnormality }\end{array}$ & Percentage \\
\hline Palka $^{22}$ & 1990 & 96 & 11 & 11.42 \\
\hline Gunduz $^{15}$ & 1998 & 102 & 16 & 15.7 \\
\hline Badovinac $^{5}$ & 2000 & 158 & 28 & 17.7 \\
\hline Alkhalaf $^{3}$ & 2002 & 118 & 12 & 10.16 \\
\hline Lissitsina $^{18}$ & 2002 & 27 & 05 & 18.5 \\
\hline Carp $^{7}$ & 2004 & 458 & 44 & 9.60 \\
\hline Quilter $^{24}$ & 2005 & 103 & 10 & 9.7 \\
\hline Sayee $^{26}$ & 2006 & 73 & 12 & 16.4 \\
\hline $\begin{array}{l}\text { Present } \\
\text { study }\end{array}$ & $\mathbf{2 0 0 7}$ & $\mathbf{7 0}$ & $\mathbf{0 9}$ & $\mathbf{1 2 . 8 5}$ \\
\hline
\end{tabular}

Table 6: Showing incidence of KF and Mosaic KF in Male Infertility

\begin{tabular}{|c|c|c|c|c|c|c|}
\hline Author & Year & Total No. of Patients & KF & Percentage & Mosaic KF & $\%$ \\
\hline Ismail $^{15}$ & 1993 & 100 & 0 & -- & 7 & 7 \\
\hline Yoshida $^{32}$ & 1997 & 1007 & 28 & 2.78 & 0 & -- \\
\hline Lissitsina $^{18}$ & 2002 & 27 & 1 & 3.70 & 3 & 11.11 \\
\hline Ambasudhan ${ }^{4}$ & 2003 & 180 & 6 & 3.33 & 2 & 1.11 \\
\hline Abdelmoula $^{\top}$ & 2004 & 51 & 6 & 11.76 & 3 & 5.88 \\
\hline Carp $^{7}$ & 2004 & 458 & 0 & -- & 3 & 0.65 \\
\hline $\mathrm{Ali}^{2}$ & 2005 & 109 & 1 & 0.91 & 0 & -- \\
\hline Quilter $^{24}$ & 2005 & 103 & 2 & 1.94 & 3 & 2.91 \\
\hline Present study & 2007 & 70 & 2 & 2.85 & 1 & 1.42 \\
\hline
\end{tabular}

Table 7: Showing incidence of Translocation in Male Infertility

\begin{tabular}{|l|c|c|c|c|}
\hline Author & Year & Total No. of Patients & Translocation & Percentage \\
\hline Pederson $^{23}$ & 1984 & 195 & 01 & 0.51 \\
\hline Baschat $^{6}$ & 1996 & 32 & 02 & 6.25 \\
\hline Yoshida $^{32}$ & 1997 & 1007 & 18 & 1.78 \\
\hline Haidl $^{13}$ & 2000 & 305 & 10 & 3.27 \\
\hline Carp $^{7}$ & 2004 & 458 & 21 & 4.58 \\
\hline Quilter $^{24}$ & 2005 & 103 & 02 & 1.94 \\
\hline Sayee $^{26}$ & 2006 & 73 & 02 & 2.73 \\
\hline Present study & $\mathbf{2 0 0 7}$ & $\mathbf{7 0}$ & $\mathbf{0 1}$ & $\mathbf{1 . 4 2}$ \\
\hline
\end{tabular}




\section{References}

[1] Abdelmoula NB., Amouri A., Portnoi MF., Saad A., Boudawara T., Nabil Mhiri M., Bahloul A., Rebai T. (2004). 'Cytogenetic and Flourescent insitu hybridization assessment of mosaicism in Klinefelter syndrome.' Ann Genet, 47 (2):163-75.

[2] Ali, Mahmood and Prabhakara MG., Babu M., Bajaj V., ManJunath GB., Vasan SS., Prasanna Kumar KM., Kumar Arun (2005). 'Cytogenetic and molecular analysis of infertile males.' :79

[3] Alkhalaf M., Varghese L., Muharib N. (2002). 'A Cytogenetic study of Kuwaiti couples with infertility and reproductive disorders: short arm deletion of chromosome 21 is associated with male infertility.' Annales de Genetique. 45(3):147-9.

[4] Ambasudhan R., Singh K., Agarwal J., Singh S., Khanna A., Sah R., Singh I., Raman R. (2003). 'Idiopathic cases of male infertility from a region in India show low incidence of Y-Chromosome microdeletion.’ J. Biosci. 28(5):605 -612.

[5] Badovinac A., Tomljanovic AB., Starcevic N., Vlastelic M., Randic L. (2000). 'Chromosome studies in patients with defective reproductive success.' American Journal of Reproductive Immunology. 44:279-83.

[6] Baschatt AA., Kupker W., Hasani S., Diedrich K., Schwinger E. (1996). 'Results of Cytogenetic analysis in men with severe subfertility prior to intracytoplasmic sperm injection.’ Hum. Reprod. 11(2):330-3.

[7] Carp H, Feldman B, Oelsner G, Schiff E (2004). Parental karyotype and subsequent live births in recurrent miscarriage. Fertility sterility, Vol 81, No 5: $1296-1301$.

[8] Duzcan F., Atmaca M., Cetin G., Bagci H. (2003). 'Cytogenetic studies in patients with reproductive failure.' Acta Obstet Gynecol Scand. $\underline{82}: 53-56$.

[9] ESRE Capri Workshop Group (2004). 'Diagnosis \& management of the infertile couple: missing information 10(4): $295-307$.

[10] Forejt J. (1974) 'Nonrandom association between a soecific autosome \& the X chromosome in meiosis $\mathrm{f}$ the male mouse-possible consequences of homologous centromere separation.' 13:241-48.

[11] Foresta Carlo (2001). 'Guidelines for the genetic diagnosis of the infertile couple' Data collected from various sources.

[12] Gunduz G., Luleci G., Baykara M. (1998). 'Cytogenetic study in 102 infertile men.' Urologia internationalis. 61(1):32-4.

[13] Haidl G., Peschaka B., Schwanitz G. (2000). 'Cytogenetic and andrological status and ICSI - results in couples with severe male factor infertility.' Asian Journal of Andrology 2:293-296.

[14] Hall J.E. (2001). 'Infertility \& Fertility control'. In Braunwald E., Fausi AS., Kasper DL., Hauser SL., Longo DL., Jameson JL. eds. Harrison's principal of internal medicine. $5^{\text {th }}$ Ed. New York: McGraw- Hill; 301-305.

[15] Ismail SR., Beheiry AH., Hashishe MM., Bahaei ME. (1993). 'Cytogenetic study in idiopathic infertile males.' Journal of the Egyptian Public Health Association 68(1-2):179-204.

[16] Israel S.L. (1967). 'Diagnosis \& treatment of menstrual Disorder and sterility' $5^{\text {th }}$ Ed: 409-410.

[17] Katagiri V., Neri QV., Kent M et al (2002a) 'Chromosomal status of infertile couples \& the offspring created by ICSI. Fertility \& sterility $\underline{78}: 16$.

[18] Lissitsina J., Mikelsaar R., Varb K., Punab M. (2002). 'Chromosomal analyses in infertile men.' Data collected from various sources.

[19] Lunenfeld B., Insler V. (1993) 'Infertility: the dimension of the problem.' $2^{\text {nd }}$ Ed: $3-10$

[20] Nishino Y., FusihiroS., Hatano K., Kawada Y. (1993) 'A case of 46,XX male.’ Article in Japanese; 39(1): 93-5.

[21] Novak's Gynecology. (2002). $13^{\text {th }}$ Ed: $973-1107$.

[22] Palka GD., Bianchi PG., Calabrese G., Guanciali B., Stuppia L., Marino M., Parruti G., Di Virgillo C., Di Sante O., Grilli A. (1990). 'Cytogenetic study of 201 subjects with altered reproductive fitness.' Minerva Ginecol. 42(8):289-92.

[23] Pedersen BS., Pedersen SS.(1984). 'Etiologic factor and subsequent reproductive performance in 195 couple with a prior history of habitual abortion' $148: 140$.

[24] Quilter C. (2005). 'Chromosomal abnormalities and male infertility.' Indian journal of medical research

[25] Quilter CR., Svennevik EC., Serhal P., Ralph D., Bahadur G., Stanhope R., Sutterlin M., Delhanty J., Taylor K. (2003). 'Cytogenetic and Y Chromosome microdeletion screening of a random group of infertile males.' Fertility and Sterility. $\quad$ 79(2):301-307.

[26] Rajangam S., Tilak P., Aurana N., Devi R. (2007). 'Karyotyping and counseling in bad obstetric history and inferlitity.' Iranian journal of reproductive medicine 5(1):7-12.

[27] Rao A. Kamini. 'The Infertility Manual' $2^{\text {nd }}$ edition:42-53,126-131 and 528-535.

[28] Speroff L, Glass R, Kase N. (1989). 'Clinical Gynaecologic Endocrinology and Infertility.' $4^{\text {th }}$ Ed. $565-582$.

[29] Van Assche E., Bonduelle M., Tournaye H., Joris H., Verheyen G.Devroey P., Van Steirteghem A., Liebaers I. (1996). 'Cytogenetics of infertile men.' Hum. Reprod, 11 Suppl 4:1-24; discussion 25-6.

[30] Wiland E., Wojda A., Kamieniczna M., Latos Bienlenska A., J drzejczak P., Kurpisz M. (2001). 'Idiopathic infertility in married couples in the light of cytogenetic analysis and sperm penetration assay.' folia Histochemica et cytobiologica. 39(1):35-41.

[31] World Health Organization. WHO Manual for the Standardised Investigation and Diagnosis of the Infertile Couple. Cambridge University Press, 2000.

[32] Yoshida A., Miura K., Shirai M. (1997). 'Cytogenetic survey of 1007 infertile males.' Urologia internationalis. 58(3):166-76.

[33] Zargar AH., Wani AI., Masoodi SR., Laway BA., Salahuddin M. (1997). 'Epidemiologic and etiologic aspects of primary infertility in the Kashmir region of India.' Fertile Steril, 68(4): 637-43. 